\title{
Influence of Abyssal Mixing on the Multilayer Circulation in the South China Sea
}

\author{
QI QUAN \\ State Key Laboratory of Tropical Oceanography, South China Sea Institute of Oceanology, Chinese Academy \\ of Sciences, Guangzhou, and Department of Ocean Science and Engineering, Southern University \\ of Science and Technology, Shenzhen, China \\ HUIJIE XUE \\ State Key Laboratory of Tropical Oceanography, South China Sea Institute of Oceanology, and Institution of South \\ China Sea Ecology and Environmental Engineering, Chinese Academy of Sciences, Guangzhou, China, and \\ School of Marine Sciences, University of Maine, Orono, Maine
}

(Manuscript received 5 February 2019, in final form 19 July 2019)

\begin{abstract}
By parameterizing the abyssal mixing as the exchange velocity (entrainment/detrainment) between the middle and deep layers of the South China Sea (SCS), its effects on the multilayer circulation are examined. Results indicate that the cyclonic circulation in the deep SCS appears only when the mixing induces an entrainment of at least $0.72 \mathrm{~Sv}\left(1 \mathrm{~Sv} \equiv 10^{6} \mathrm{~m}^{3} \mathrm{~s}^{-1}\right)$ from the deep to the middle layer, which is equivalent to a diapycnal diffusivity of $0.65 \times 10^{-3} \mathrm{~m}^{2} \mathrm{~s}^{-1}$ or a net input rate of gravitational potential energy (GPE) of $6.89 \mathrm{GW}$, respectively. It is also found that tidal mixing in the SCS is stronger than the threshold for the generation of the cyclonic abyssal circulation, but the pattern and evolution of the deep circulation and meridional overturning circulation also depend on the spatiotemporal variability of the mixing. Moreover, the abyssal mixing is able to intensify the anticyclonic circulation in the middle layer but weaken the cyclonic circulation in the upper layer. Vorticity analysis suggests that the upward net flux induced by the abyssal mixing leads to vortex stretching (squeezing) and modulates the pressure gradient by redistributing the layer thickness, hence affects the pattern and strength of the circulation in the middle (deep) layer of the SCS, respectively. The depth-integrated effect of the thickness variation can modulate the pressure gradient across all layers and hence influence the upper-layer circulation.
\end{abstract}

\section{Introduction}

Mixing in the ocean occurs at multiscales and is closely associated with various dynamical processes ranging from eddy stirring, internal wave breaking, turbulence, and down to molecular diffusion. In the abyssal ocean, diapycnal mixing is of vital importance in maintaining the stratification and meridional overturning circulation (MOC) and hence is able to significantly affect both local and global climate through heat transport (e.g., Rahmstorf 2003; Jayne 2009; Talley 2013; Mashayek et al. 2015). Munk (1966) estimated a diapycnal diffusivity of $10^{-4} \mathrm{~m}^{2} \mathrm{~s}^{-1}$ to maintain the abyssal stratification against global upwelling associated with $25 \mathrm{~Sv}\left(1 \mathrm{~Sv} \equiv 10^{6} \mathrm{~m}^{3} \mathrm{~s}^{-1}\right)$ of deep water formation. Subsequent observations indicate that the diapycnal diffusivity ranges from $10^{-5} \mathrm{~m}^{2} \mathrm{~s}^{-1}$

Corresponding author: Huijie Xue, huijiexue@scsio.ac.cn above the smooth abyssal plains (e.g., Ledwell et al. 1993; Polzin et al. 1997) to more than $10^{-3} \mathrm{~m}^{2} \mathrm{~s}^{-1}$ over the rough topography, such as seamounts, ridges, and canyons (e.g., Ferron et al. 1998; Ledwell et al. 2000; Waterhouse et al. 2014).

The thermohaline circulation requires external sources of mechanical energy to support mixing for sustaining the basic stratification (Huang 2009). In the abyssal ocean, diapycnal mixing is supported mainly by the tidal energy dissipation, which supplies about 0.6$0.9 \mathrm{TW}\left(1 \mathrm{TW}=10^{12} \mathrm{~W}\right)$ for abyssal mixing and accounts for about half of $2.1 \mathrm{TW}$ required to maintain the global MOC (Munk and Wunsch 1998; Wunsch and Ferrari 2004). Additionally, the global energy of internal lee waves induced by quasi-steady flow and mesoscale eddies over rough topography is estimated to be about 0.2-0.4 TW (Scott et al. 2011; Nikurashin and Ferrari 2013). Generally, the near-inertial energy generated by 
wind is thought to dissipate mostly within the upper ocean (Alford et al. 2016). However, the near-inertial waves were observed to propagate downward past $3000 \mathrm{~m}$ near the Mendocino Escarpment (Alford 2010). Furthermore, Jing and $\mathrm{Wu}$ (2014) found that in the Kuroshio extension region, about $45 \%-62 \%$ of the local near-inertial wind work radiates into the deep ocean and accounts for $42 \%-58 \%$ of the energy required to furnish mixing there.

The South China Sea (SCS) is the largest marginal sea in the western Pacific, and it is connected with the western Pacific Ocean via the Luzon Strait, the only deep passage. With the complicated topography in the SCS, the enhanced diapycnal mixing is observed to be on the order of $10^{-3} \mathrm{~m}^{2} \mathrm{~s}^{-1}$, two orders of magnitude larger than that over the smooth bathymetry in the North Pacific (Tian et al. 2009). In the Luzon Strait and Zhongsha Islands area, the intensive diapycnal mixing can even reach $3 \times 10^{-2} \mathrm{~m}^{2} \mathrm{~s}^{-1}$ (Yang et al. 2016). The enhanced diapycnal mixing in the SCS and the Luzon Strait is mainly attributed to the baroclinic tidal dissipation (Alford et al. 2011, 2015). Energetic internal tides occur when the barotropic tides propagate over the rough topography in the Luzon Strait. Part of the internal tides dissipates locally near the generation sites and the remaining part propagates eastward into the Pacific and westward into the SCS (Niwa and Hibiya 2004; Jan et al. 2007). The northwestwardpropagating internal tides evolve into internal solitary waves after encountering the steep slope and the Dongsha Islands in the northern SCS (Lien et al. 2005), which makes the SCS one of the most active regions in the World Ocean for such waves (Zhao et al. 2004). According to the internal tide energy budget of the SCS and the Luzon Strait by Wang et al. (2016), the dissipation rate of the baroclinic energy in the SCS is $15.98 \mathrm{GW}\left(1 \mathrm{GW}=10^{9} \mathrm{~W}\right)$ in winter and $18.22 \mathrm{GW}$ in summer, in which the local conversion rate from barotropic to baroclinic tidal energy is about half of the divergence of baroclinic energy flux. It suggests that the remotely generated internal tides are the dominant contributor to the baroclinic tidal dissipation in the SCS.

Using numerical models, Zhao et al. (2014) and Wang et al. (2017) found that the enhanced diapycnal mixing in the SCS and the Luzon Strait is able to sustain a deep-layer baroclinic pressure gradient across the Luzon Strait, which drives an overflow from the Pacific into the SCS (Qu et al. 2006; Tian et al. 2006; Yang et al. 2010). To balance the descending mass, the deep SCS water must be lightened through diapycnal mixing, upwell somewhere else within the basin $(\mathrm{Qu}$ et al. 2006), and finally flow back to the Pacific via the middle layer of the Luzon Strait (Zhu et al. 2016;
Liu and Gan 2017). This exchange process makes the SCS work as a "mixing mill" for the water mass transformation in the Pacific Ocean. Moreover, in conjunction with the monsoon, the sandwich-like water exchange in the Luzon Strait leads to a unique multilayer circulation system in the SCS, namely, the cyclonic circulation in the upper and deep layers but anticyclonic circulation in the middle layer (Lan et al. 2013; Shu et al. 2014; Xu and Oey 2014; Gan et al. 2016; Zhu et al. 2017).

Since the diapycnal mixing is not well understood, its parameterization in ocean general circulation models (OGCMs) is still one of the greatest challenges in physical oceanography. For simplification, in theoretical researches, diapycnal mixing has been represented by an upward flux between isopycnal layers. In the classical model of Stommel and Arons (1960), the abyssal circulation on a sphere is driven by the spatially uniform upwelling through the interface, with an intensified western boundary current (WBC) flowing southward to supply the poleward water in the interior basin. In the light of Stommel-Arons model, Xiao et al. (2013) constructed a diagnostic model of the SCS abyssal circulation including the effects of tidal mixing and eddy-driven mixing. In their model, the tidal mixing was parameterized following the method of St. Laurent et al. (2002). Part of the energy was used for mixing and resulted in the entrainment from the abyssal to upper layers, which contributed to the generation of the cyclonic circulation in the deep SCS. Their insightful work validated the theory of Stommel and Arons in the marginal sea and highlighted the impact of mixing on the SCS abyssal circulation. However, some important issues still remain to be addressed, such as how strong the mixing intensity should be to drive the cyclonic circulation in the deep SCS, whether the circulation is sensitive to spatiotemporal variability of mixing, and whether the abyssal mixing could influence the SCS circulation in the upper and middle layers.

The objectives for this study are 1) to test the sensitivity of the sandwich-like SCS circulation, especially the deep-layer circulation, to the intensity and spatiotemporal variability of the abyssal mixing, 2) to assess the contribution of tidal mixing to the SCS abyssal circulation, and 3) to give a dynamic explanation of how the abyssal mixing influences the multilayer SCS circulation system. The rest of this paper is organized as follows: the model configuration and parameterization scheme are introduced in section 2. Section 3 presents the results of numerical experiments. The relevant dynamic mechanism is discussed in section 4. Finally, section 5 is the summary of the study. 


\section{Data and methods}

\section{a. Layered ocean model}

Different from the fully three-dimensional models, layered ocean models with simplified frameworks are able to elucidate the concerned dynamics of the oceans by excluding the impacts from other processes. Hence, they become very useful tools to study the dynamical mechanism of the SCS circulation (e.g., Wang et al. 2006; Cai et al. 2007; Yang et al. 2015). By adding the fourth layer to represent the abyssal SCS, the ocean model used here is further developed from our previous three-layer model (Quan and Xue 2018), which has been validated to well reproduce the SCS circulation in the upper and middle layers and reveal the dynamical coupling between them. Note that both models are modified from the layered Indian Ocean model (McCreary and Kundu 1988, 1989; McCreary et al. 1993) and its ramification, the 4.5-layer SCS model (Yu et al. 2007, 2008; Yaremchuk et al. 2009). Each active layer in the model has a constant density and the density differences between layers are also constant, which helps the model to reach equilibrium quickly. The governing equations are as follows

$$
\begin{aligned}
& \left(h_{i} \mathbf{v}_{i}\right)_{t}+\nabla \cdot\left(\mathbf{v}_{i} h_{i} \mathbf{v}_{i}\right)+f \mathbf{k} \times h_{i} \mathbf{v}_{i}+h_{i}\left\langle\nabla P_{i}\right\rangle=\boldsymbol{\tau}_{i-1 i}-\boldsymbol{\tau}_{i i+1}+v \nabla^{2}\left(h_{i} \mathbf{v}_{i}\right)-\mathbf{v}_{i} w_{i-1 i} \theta\left(w_{i-1 i}\right) \\
& \quad-\mathbf{v}_{i-1} w_{i-1 i} \theta\left(-w_{i-1 i}\right)+\mathbf{v}_{i+1} w_{i i+1} \theta\left(w_{i i+1}\right)+\mathbf{v}_{i} w_{i i+1} \theta\left(-w_{i i+1}\right),
\end{aligned}
$$

$$
\left(h_{i}\right)_{t}+\nabla \cdot\left(h_{i} \mathbf{v}_{i}\right)=-w_{i-1 i}+w_{i i+1},
$$

where $h_{i}$ and $\mathbf{v}_{i}$ are the layer thickness and horizontal velocity, respectively, and the subscript $i(i=1,2,3,4)$ is the layer index; $f$ is the Coriolis parameter varying with the latitude; $v=5 \times 10^{3} \mathrm{~m}^{2} \mathrm{~s}^{-1}$ is the coefficient of eddy viscosity; $w_{i i+1}$ is the exchange velocity $(\mathrm{EV})$ between the $i$ th and $(i+1)$ th layers, and $\theta$ is the heaviside step function defined as $\theta(x)=1$ if $x>0$ and $\theta(x)=0$ if $x \leq 0$.

In Eq. (1), the terms, from left to right, are the acceleration (ACC), advection (ADV), Coriolis acceleration (COR), pressure gradient (PG), wind stress (WS; only for the first layer), interface friction (IF; for the water boundary between layers), or bottom friction (BF; if the layer bottom is the sea floor), horizontal diffusion (HD), and entrainment/detrainment-induced momentum exchange between layers (EDIME).

The PG term in each layer is as follows

$$
\left\langle\nabla P_{i}\right\rangle=\sum_{n=1}^{i} g_{n-1}^{\prime} \nabla \zeta_{n},
$$

where $\zeta_{i}$ is the surface/interface elevation and is given by the following,

$$
\zeta_{i}=\sum_{i}^{4} h_{i}+H
$$

Here, $H$ is the static water depth; $g_{0}^{\prime}=g=9.8 \mathrm{~m} \mathrm{~s}^{-2}$ is the gravitational acceleration; $g_{i}^{\prime}=g\left(\Delta \rho_{i i+1} / \rho_{0}\right)$ is the reduced gravitational accelerations in the $(i+1)$ th layer, $\Delta \rho_{i i+1} / \rho_{0}$ is the normalized density difference between the $i$ th and $(i+1)$ th layer. In this study, $\Delta \rho_{12} / \rho_{0}=0.0044$, $\Delta \rho_{23} / \rho_{0}=0.0038$, and $\Delta \rho_{34} / \rho_{0}=0.0018$, which are based on the climatological density profile in the central SCS basin from the World Ocean Atlas 2013 (WOA13; Locarnini et al. 2013; Zweng et al. 2013) and the initial layering specified in Table 1.

The variable $\boldsymbol{\tau}_{01}=\boldsymbol{\tau}_{\text {wind }}$ is the wind stress calculated as

$$
\tau_{\text {wind }}=\frac{\rho_{a}}{\rho_{0}} C_{D} \mathbf{W}|\mathbf{W}|,
$$

where $\rho_{a}=1.23 \mathrm{~kg} \mathrm{~m}^{-3}$ is the air density, $\rho_{0}=1025 \mathrm{~kg} \mathrm{~m}^{-3}$ is the reference density of seawater, and $C_{D}$ is the drag coefficient calculated following Large et al. (1994) as

$$
C_{D}=\left(\frac{2.7}{|\mathbf{W}|}+0.142+0.0764|\mathbf{W}|\right) \times 10^{-3},
$$

where $\mathbf{W}$ is the wind velocity and $|\mathbf{W}|$ is the wind speed.

The term $\boldsymbol{\tau}_{i i+1}(i=1,2,3,4)$ is either the IF for the water boundary between layers or $\mathrm{BF}$ if the layer bottom is the seabed (note that $\tau_{45}$ is the $\mathrm{BF}$ for the fourth layer), which follows the quadratic law (Cai et al. 2007) as

$$
\boldsymbol{\tau}_{i i+1}=C\left(\mathbf{v}_{i}-\mathbf{v}_{i+1}\right)\left|\left(\mathbf{v}_{i}-\mathbf{v}_{i+1}\right)\right|,
$$

where $C=5 \times 10^{-5}\left(1.85 \times 10^{-3}\right)$ is the IF $(\mathrm{BF})$ coefficient; $\mathbf{v}_{5}$ is zero.

\section{b. Entrainment and detrainment}

Entrainment and detrainment due to wind stirring is determined in a manner similar to that in Kraus and Turner (1967) and McCreary and Kundu (1989) as

$$
w_{e}=\frac{h_{1 E}^{n}-h_{1}^{n-1}}{\Delta t},
$$


TABLE 1. Separation of layers and layer thickness; $H$ is the static water depth from ETOPO1 and $h_{i}(i=1,2,3,4)$ denotes the initial thickness of layer $i$ in the model. Generally, $h_{i}$ is determined by $H$ and $\sum_{i=1}^{4} h_{i}=H$. However, to simplify the topography in the regions where $H$ is too shallow $(<50 \mathrm{~m})$ or too deep $(>4000 \mathrm{~m})$, the minimum and maximum static water depth in the model is separately reset as 50 and $4000 \mathrm{~m}$, respectively. The maximum initial thickness is set as $200,500,800$, and $2500 \mathrm{~m}$ for the first to fourth layer, respectively.

\begin{tabular}{lcccccr}
\hline \hline$H(\mathrm{~m})$ & $0<H \leq 50$ & $50<H \leq 200$ & $200<H \leq 700$ & $700<H \leq 1500$ & $1500<H \leq 4000$ & $4000<H$ \\
\hline$h_{1}(\mathrm{~m})$ & 50 & $H$ & 200 & 200 & 200 & 200 \\
$h_{2}(\mathrm{~m})$ & 0 & 0 & $H-200$ & 500 & 500 & 500 \\
$h_{3}(\mathrm{~m})$ & 0 & 0 & 0 & $H-700$ & 800 & 800 \\
$h_{4}(\mathrm{~m})$ & 0 & 0 & 0 & 0 & $H-1500$ & 2500 \\
\hline
\end{tabular}

where $\Delta t$ is the time step, $h_{1}^{n-1}$ denotes the first layer thickness at the previous time step, and $h_{1 E}^{n}$ denotes the first layer thickness at the present time step. The specification of $h_{1 E}^{n}$ is only determined by the net rate of generation of turbulent kinetic energy as

$$
E=m u_{*}^{3}-\varepsilon h_{1}^{n-1},
$$

where $m u_{*}^{3}$ parameterizes the turbulence generated by wind stirring and $-\varepsilon h_{1}^{n-1}$ is the rate of viscous dissipation. $m$ is the wind stirring coefficient and set as 0.5 following Yu et al. (2007), $u_{*}$ is the friction velocity, and $\varepsilon=10^{-8} \mathrm{~m}^{2} \cdot \mathrm{s}^{-3}$ is a background dissipation coefficient (McCreary and Kundu 1989). If the turbulence is difficult to occur (i.e., $E \leq 0$ ), the layer instantly detrains to the Monin-Obukhov depth as

$$
h_{1 E}^{n}=\frac{m u_{*}^{3}}{\varepsilon},
$$

obtained by setting $E=0$ in Eq. (9); otherwise,

$$
h_{1 E}^{n}=h_{1}^{n-1}-\frac{E \cdot \Delta t}{\frac{1}{2} g \frac{\Delta \rho_{12}}{\rho_{0}} h_{1}^{n-1}},
$$

which is obtained by equating the rate of potential energy increase, $(1 / 2) g\left(\Delta \rho_{12} / \rho_{0}\right) h_{1}^{n-1}\left(d h_{1} / d t\right)$, to the rate of generation of turbulent kinetic energy $E$.

Entrainment and detrainment due to shear instability is defined following McCreary and Kundu (1989) and Yaremchuk et al. (2009) as

$$
w_{\mathrm{si}}=\left\{\begin{array}{l}
\frac{\left(H_{e}-h_{i}^{n}\right)^{2}}{t_{e} H_{e}} \theta\left(H_{e}-h_{i}^{n}\right) \\
-\frac{\left(h_{i}^{n}-H_{e}\right)^{2}}{t_{e} H_{e}} \theta\left(h_{i}^{n}-H_{e}\right)
\end{array},\right.
$$

where $t_{e}$ is the relaxation time scale. The term $H_{e}=\max \left(h_{i}^{n-1}, H_{r}\right)$ is the maximum between the thickness at the previous time step (i.e., $h_{i}^{n-1}$ ) and

$$
H_{r}=R_{i} \frac{\rho_{0}}{g \Delta \rho_{i i+1}}\left(\mathbf{v}_{i+1}-\mathbf{v}_{i}\right)^{2} .
$$

The term $H_{r}$ represents the thickness below which the flow becomes supercritical when the bulk Richardson number criterion $R_{i}=\left[g \Delta \rho_{\mathrm{ii}+1} / \rho_{0}\left(\mathbf{v}_{i+1}-\mathbf{v}_{i}\right)^{2}\right] H_{r}$ is 0.75 (Yaremchuk et al. 2009). If the instantaneous thickness $h_{i}^{n}$ is larger than $H_{e}$, detrainment occurs and vice versa.

In light of the classical abyssal circulation model of Stommel and Arons (1960), we prescribed the mixinginduced entrainment (i.e., $w_{m}$ ) from the fourth layer to the third layer in the model, which is crucial for this study and calculated using three methods for different purposes.

First, we assumed that the entrainment is a constant, which can be written as

$$
w_{m}=\frac{Q}{S},
$$

where $Q$ is the upwelling flux to balance the deep overflow through the Luzon Strait (Qu et al. 2006) and $S$ is the area of the interface between the third and fourth layers.

Second, following McDougall and Dewar (1998) and using a map of the tide-induced, near-bottom, diapycnal diffusivity read from Wang et al. (2017), the entrainment solely resulted from the tidal mixing was written as

$$
w_{m}=\frac{\kappa_{t}}{h_{4}^{n}} \frac{\rho_{0}}{\Delta \rho_{34}},
$$

where $\kappa_{t}$ is the tide-induced diapycnal diffusivity.

Last, we constructed a spatiotemporally varying $w_{m}$ in reference to the map of abyssal upwelling in the SCS from the HYCOM reanalysis dataset GLBa0.08 (Shu et al. 2014) as

$$
w_{m}=\frac{Q_{\mathrm{SODA}}}{\iint_{S} F(x, y) d x d y} F(x, y),
$$

where $F(x, y)=e^{\nabla H / 0.06}$ is a distribution function related to the terrain gradient $\nabla H$ and $Q_{\text {SODA }}$ represents the 
annual cycle of the Luzon Strait transport below $1500 \mathrm{~m}$ from the Simple Ocean Data Assimilation (SODA; Carton et al. 2000a,b).

Thus, $w_{12}, w_{23}$, and $w_{34}$ are given by the following as

$$
\begin{aligned}
& w_{12}=w_{e}+w_{s 1}, \\
& w_{23}=w_{s 2}, \quad \text { and } \\
& w_{34}=w_{s 3}+w_{m} .
\end{aligned}
$$

\section{c. Model setup}

The computational domain (Fig. 1) is similar to Quan and Xue (2018) and the original water depth is from ETOPO1 (Amante and Eakins 2009). In reference to the layering of the SCS in Gan et al. (2016), we further divided the upper layer $(0-750 \mathrm{~m})$ into two layers in our model due to the difference in forcing: the wind-driven first layer with the maximum initial thickness of $200 \mathrm{~m}$ to represent the mean thermocline depth (Chu et al. 1999; Cai et al. 2007; Yang et al. 2015), and the second layer driven by rising and falling of the thermocline (i.e., the interface between the first and second layers), with the maximum initial thickness of $500 \mathrm{~m}$. The middle layer $(750-1500 \mathrm{~m})$ of the sandwich-like structure is represented by the third layer in our model, which has the maximum initial thickness of $800 \mathrm{~m}$. The fourth layer represents the deep layer of the SCS and the maximum initial thickness is $2500 \mathrm{~m}$. Details of the initial layering are listed in Table 1. Hereafter we use the first, second, third, and fourth to refer to the model layers, whereas the upper (first + second), middle (third), and deep (fourth) to refer to the SCS sandwich-like structure.

The open boundaries north of the Taiwan Island and east of the Luzon Island are set to allow for the lateral forcing from the Kuroshio. Another two open boundaries are set in the Karimata Strait and the Mindoro Strait, respectively. At the solid wall, a free-slip boundary condition is used and the velocity normal to the boundary is set as zero. The resolution of the model is $0.1^{\circ} \times 0.1^{\circ}$ and the time step is $10 \mathrm{~s}$.

\section{d. Forcing}

The climatological monthly wind from the crosscalibrated multiplatform (CCMP; Atlas et al. 2011) is adopted in our model, which has a horizontal resolution of $0.25^{\circ} \times 0.25^{\circ}$ and is interpolated onto the model grid.

The climatological monthly transports through the open boundaries A, C, and D (the red solid lines in Fig. 1) are extracted from $\mathrm{Yu}$ et al. (2007), which are based on the data assimilative model results of Yaremchuk and $\mathrm{Qu}$ (2004). The transport at B is geostrophically adjusted by the model itself (Hurlburt and Thompson 1980).

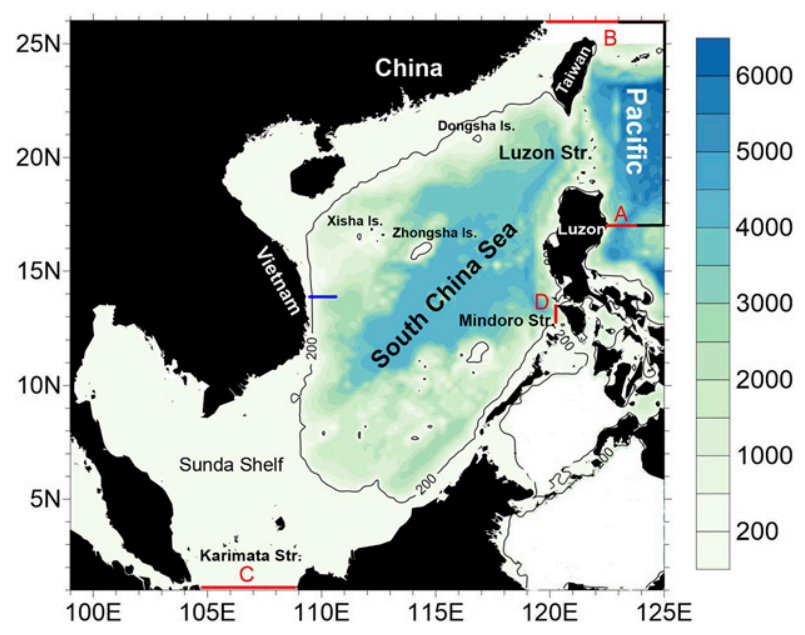

FIG. 1. Model domain and topography $(\mathrm{m})$. The black solid line is the 200-m isobath. The red solid lines with A, B, C, and D refer to the open boundaries in the model. The blue solid line denotes the transect at $13.5^{\circ} \mathrm{N}, 109.6^{\circ}-110.6^{\circ} \mathrm{E}$.

Transports imposed at the open boundaries are fulldepth values so they need to be allocated into each layer. In reference to the observations and previous model results (e.g., Gilson and Roemmich 2002; Cai et al. 2007), the vertical partition of the Kuroshio transport at A is set as 2/3,2/9, and 1/9 for the first, second, and third layer, respectively, while the transport for the fourth layer due to the deep current west of the Philippine basin (Zhou et al. 2018) is set as $-1 / 9$ of the Kuroshio transport. For $\mathrm{C}$ and $\mathrm{D}$, the transports are only imposed in the first layer due to the shallow water depth.

The model is spun up from a static state and runs for 20 years. The outputs based on a 3-day sampling from the 11th to 20 th model years are used for analysis.

\section{Results}

\section{a. Impact of abyssal mixing intensity on the SCS circulation}

In this study, we use $w_{m}$ based on Eq. (14) to test the sensitivity of the SCS circulation to the mixing intensity. After taking the deep layer into account, the circulations in the upper and middle layers of the SCS are similar to those based on the three-layer model in our previous study (Quan and Xue 2018; not shown). For the deep layer, it is found that the basin-scale circulation is anticyclonic (Figs. $2 \mathrm{a}$ and $3 \mathrm{a}$ ) when $Q=0$ (i.e., $w_{m}=0$ ), similar to that in the middle layer. As a result, the deep overflow reverses and flows out of the SCS through the Luzon Strait. Moreover, the net flux between the middle and deep layers is downward. Except for the narrow area along the northern slope, the downward 

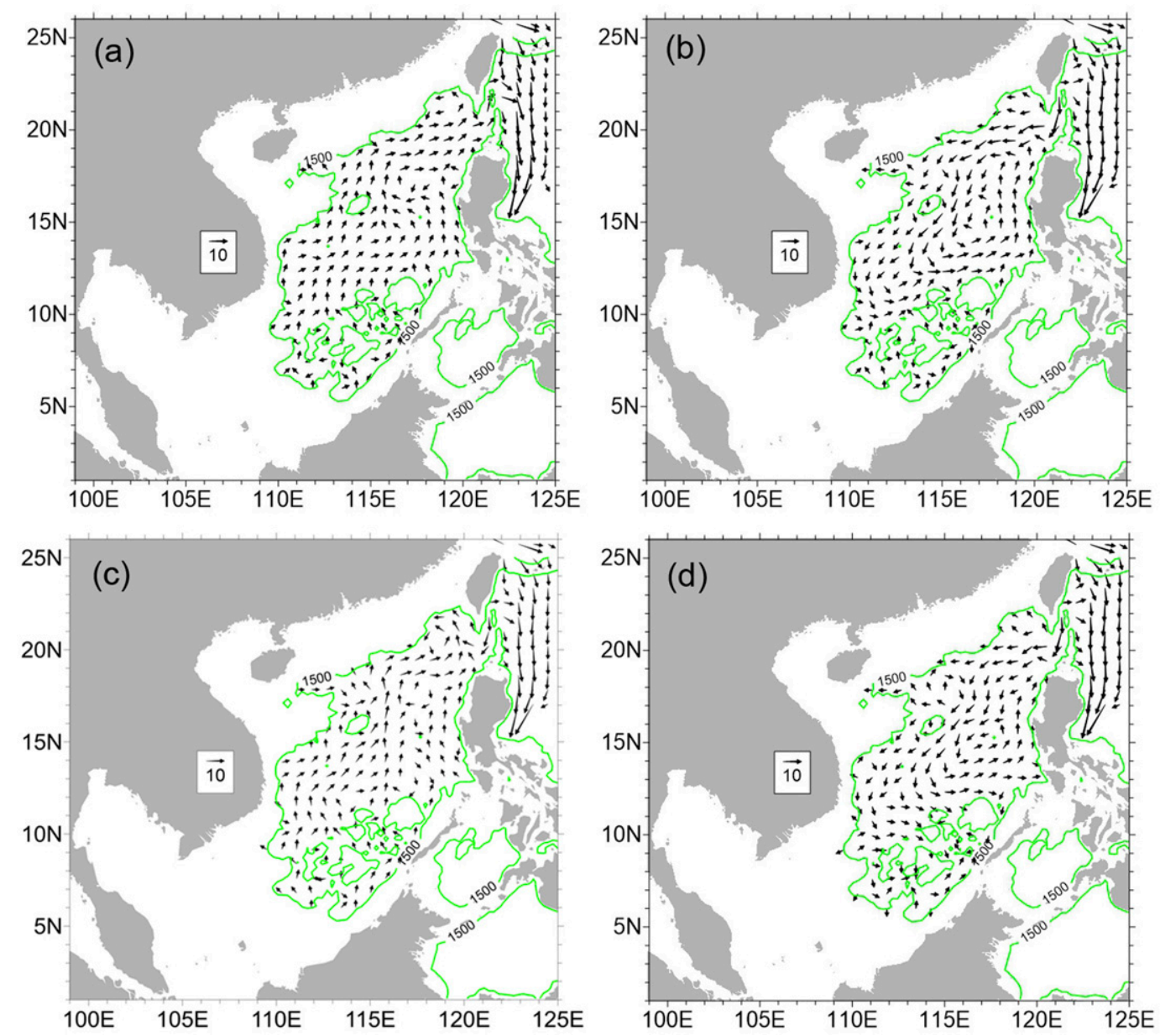

FIG. 2. Layer-integrated circulation $\left(\mathrm{m}^{2} \mathrm{~s}^{-1}\right)$ in the deep SCS in winter for (a) $Q=0$, (b) $Q=1 \mathrm{~Sv}$, (c) $Q=Q_{\text {tide }}$, and (d) $Q=Q_{\text {SODA. }}$.

EV occupies most of the basin, with the maximum of $-0.05 \times 10^{-5} \mathrm{~m} \mathrm{~s}^{-1}$ northeast of the Zhongsha Islands in winter (Fig. 4a) and $-0.02 \times 10^{-5} \mathrm{~m} \mathrm{~s}^{-1}$ east of Vietnam in summer (Fig. 5a).

As the mixing is gradually strengthened ( $Q$ increases), the abyssal circulation tends to become cyclonic (take $Q=1 \mathrm{~Sv}$ for example; Figs. $2 \mathrm{~b}$ and $3 \mathrm{~b}$ ), with the deep water flowing into the SCS through the Luzon Strait. The abyssal circulation is stronger in winter than in summer. Moreover, the upward EV dominates between the middle and deep layers, with the maximum of $0.5 \times 10^{-5} \mathrm{~m} \mathrm{~s}^{-1}$ west of the Luzon Strait (Figs. $4 \mathrm{~b}$ and $5 \mathrm{~b}$ ), which leads to a net flux entrained from the deep to the middle layer.

By increasing the value of $Q$, we conducted a series of experiments and established a regression equation as

$$
\Omega=4.03 \times Q_{\text {net }}-2.91,
$$

where $\Omega$ is the basin-integrated vorticity of the abyssal circulation and $Q_{\text {net }}=\iint_{S} w_{34} d x d y$ is the net vertical flux between the middle and deep layers (Fig. 6a). According to Eq. (20), when $Q_{\text {net }}>0.72 \mathrm{~Sv}$, the abyssal circulation is cyclonic $(\Omega>0)$; otherwise, it is anticyclonic $(\Omega<0)$. In the previous studies (Tian et al. 2006; Qu et al. 2006; Zhou et al. 2014; Wang et al. 2017; Liu and Gan 2017), the estimations of the deep overflow through the Luzon Strait range from 0.8 to $2.5 \mathrm{~Sv}$, larger than the determined threshold, and most of the studies show that there is a basin-scale cyclonic circulation in the deep SCS (Wang et al. 2011; Lan et al. 2013; Shu et al. 2014; Gan et al. 2016).

Huang (1999) pointed out that the thermohaline circulation requires external sources of mechanical energy to support mixing to maintain the basic stratification. According to Guan and Huang (2008), the rate of gravitational potential energy (GPE) in the fourth model layer can be calculated as

$$
E_{m}=w_{34} \Delta \rho_{34} g D L^{2}
$$



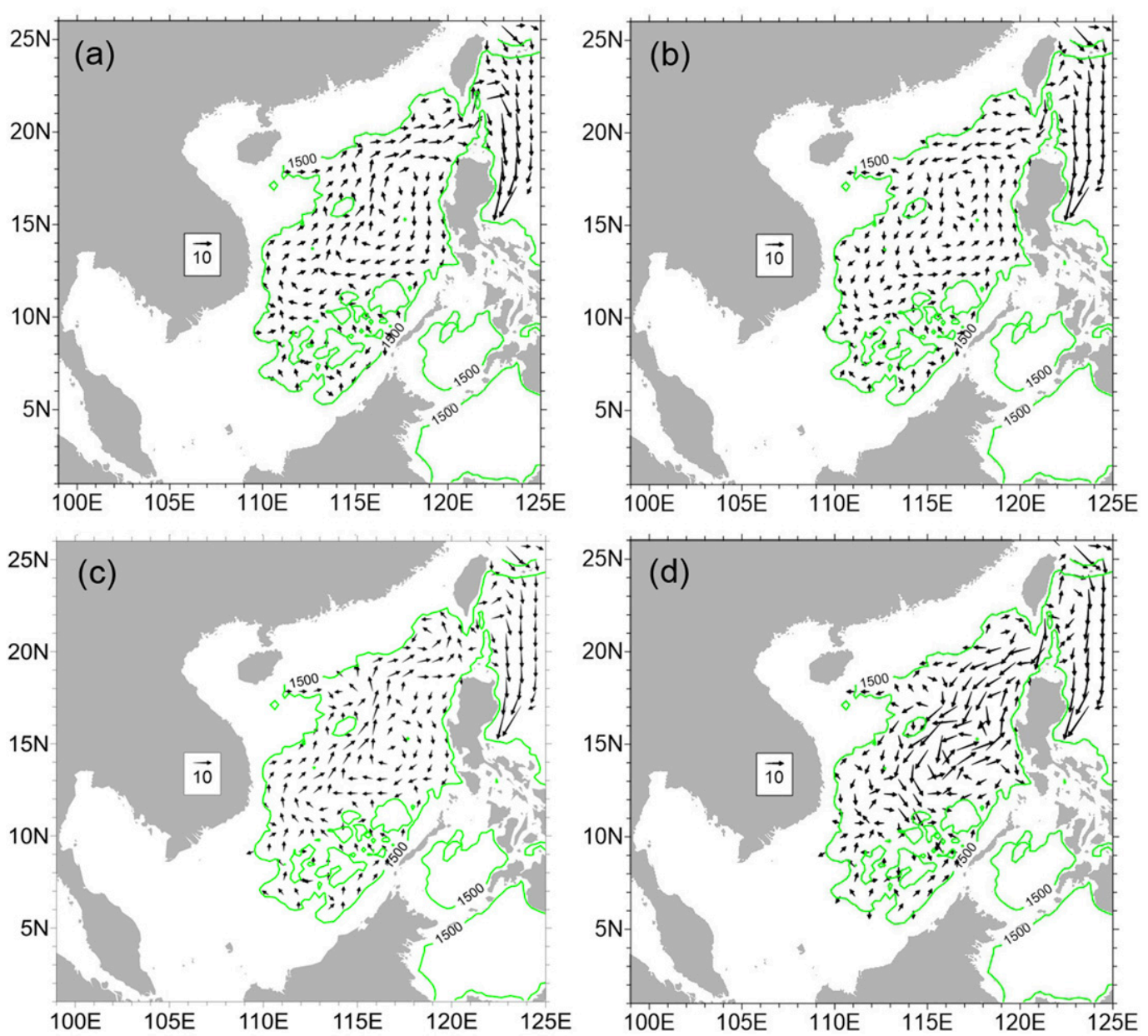

FIG. 3. As in Fig. 2, but for summer.

where $D(L)$ is the vertical (horizontal) scale of the layer. According to Eq. (21), the external mechanical energy for supporting the abyssal mixing in each experiment can be estimated (Fig. 6b) and its regression relationship with the flux between the middle and deep layers is established as

$$
E_{m}=7.45 \times Q_{\mathrm{net}}+1.53 .
$$

Hence, at least $6.89 \mathrm{GW}$ of the external mechanical energy is required for the generation of the cyclonic circulation in the deep SCS.

Furthermore, according to Qu et al. (2006), the diapycnal diffusivity can be calculated as

$$
\kappa_{v}=\frac{Q_{\text {net }} \Delta \rho_{34}}{S \partial \rho / \partial z} .
$$

Based on the determined threshold of $Q_{\text {net }}$, the basinaveraged diapycnal diffusivity should be at least $0.65 \times$ $10^{-3} \mathrm{~m}^{2} \mathrm{~s}^{-1}$. This value is smaller than $1.5 \times 10^{-3} \mathrm{~m}^{2} \mathrm{~s}^{-1}$ estimated by Qu et al. (2006) and $O\left(10^{-2}\right) \mathrm{m}^{2} \mathrm{~s}^{-1}$ by Yang et al. (2016), suggesting that the actual mixing in the deep SCS is much stronger than the threshold needed for the generation of the cyclonic abyssal circulation.

Our results indicate that the abyssal mixing plays a critical role in determining the pattern of the circulation in the deep SCS. Moreover, the abyssal mixing can also affect the SCS circulation in the middle and even upper layers. By calculating the WBC transports at $13.5^{\circ} \mathrm{N}$ section east of Vietnam (blue solid line in Fig. 1; note that the section is moved northeastward in the fourth layer due to topography and the location of the deep WBC) as the index of circulation intensity, we found that the climatological circulation in the middle (upper) layer is strengthened by $35.9 \%$ (weakened by $6.0 \%$ ) after the abyssal mixing is considered (take $Q=1 \mathrm{~Sv}$ for example; compare Figs. 7a and 7b). Meanwhile, the relative change of the Luzon Strait transport is $-6.3 \%$, $33.7 \%$, and $-1700 \%$ for the upper, middle, and deep 

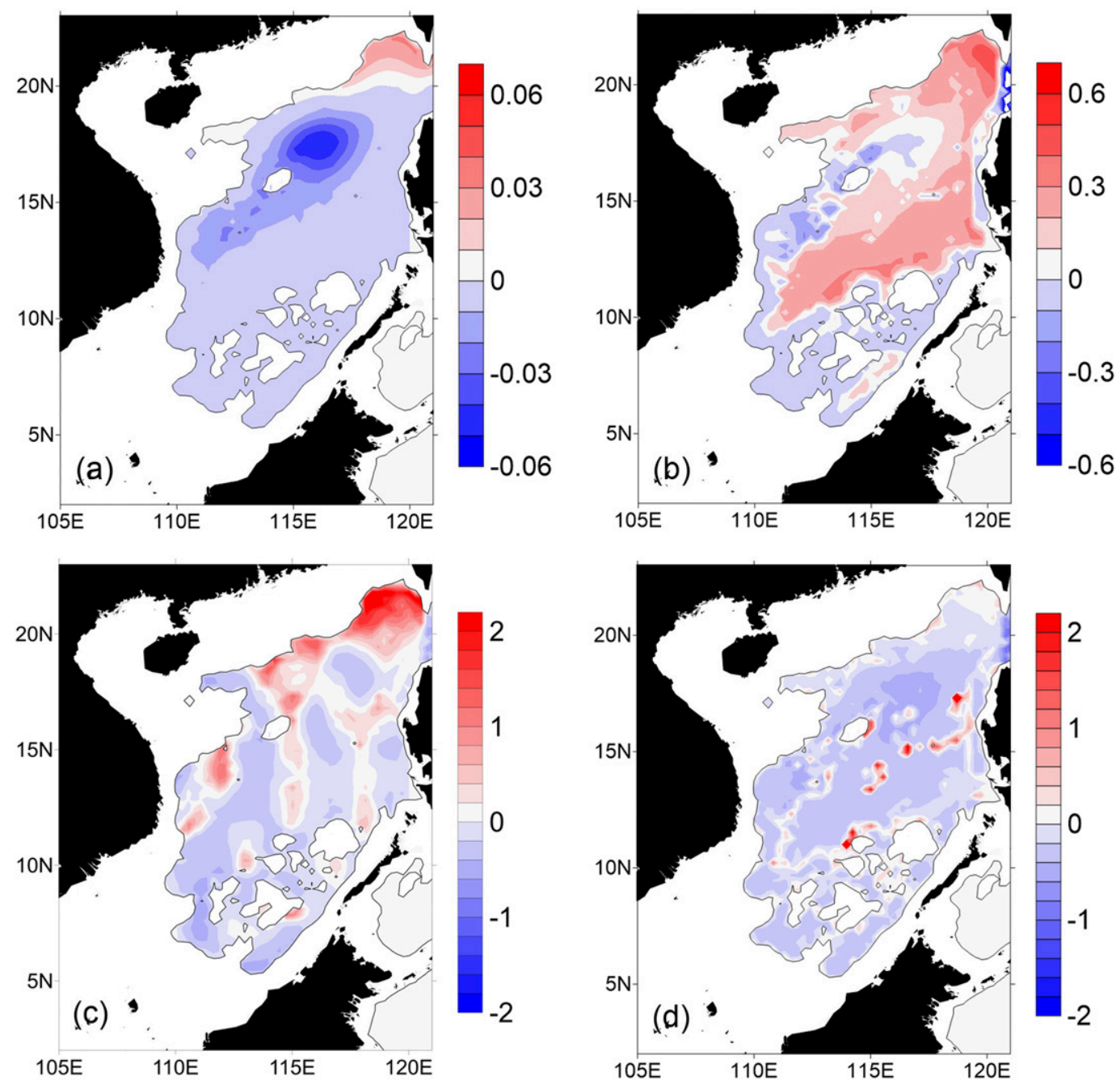

FIG. 4. Shown is $w_{34}\left(10^{-5} \mathrm{~m} \mathrm{~s}^{-1}\right)$ in winter for (a) $Q=0$, (b) $Q=1 \mathrm{~Sv}$, (c) $Q=Q_{\text {tide, }}$, and (d) $Q=Q_{\text {SODA }}$.

layer, respectively. It suggests that the abyssal mixing can have a full-depth effect on the water exchange between the SCS and the Pacific Ocean.

\section{b. Contribution of tidal mixing to the SCS abyssal circulation}

In the abyssal ocean, diapycnal mixing is supported mainly by the tidal energy dissipation. Since we have determined the critical amount of mixing-induced flux for the generation of the cyclonic circulation in the deep SCS, a question naturally follows is how much the tidal mixing can actually contribute to diapycnal mixing and hence the deep circulation. Figure 8 shows the map of tide-induced, near-bottom, diapycnal diffusivity read from Fig. 1 in Wang et al. (2017). It is found that the strongest tidal mixing occurs near the Luzon Strait and the Zhongsha Islands, which can reach $O\left(10^{-2}\right) \mathrm{m}^{2} \mathrm{~s}^{-1}$. In the slope region and the seamount areas in the middle and southern SCS, the diffusivity is about $O\left(10^{-3}-10^{-2}\right) \mathrm{m}^{2} \mathrm{~s}^{-1}$, while that in the smooth basin is about $O\left(10^{-4}-10^{-3}\right) \mathrm{m}^{2} \mathrm{~s}^{-1}$.

We then used Eq. (15) to calculate the EV between the middle and deep layers of the SCS, and the net upward flux is about $0.91 \mathrm{~Sv}\left(Q_{\text {tide }}\right)$. Based on the threshold we have determined, the tidal mixing is supposed to be strong enough for the generation of the cyclonic circulation in the deep SCS. However, only a subbasin-scale cyclonic circulation occurs west of the Luzon Strait but the basin-scale circulation remains anticyclonic in this case (Figs. $2 \mathrm{c}$ and $3 \mathrm{c}$ ). For the water exchange between the middle and deep layers, the upward EV can reach about $2.0 \times 10^{-5} \mathrm{~m} \mathrm{~s}^{-1}$ but it concentrates in the limited regions, whereas the downward EV occupies most of the basin (Figs. 4c and 5c).

The results suggest that the intensity of the abyssal mixing is not a sufficient condition for the generation of 

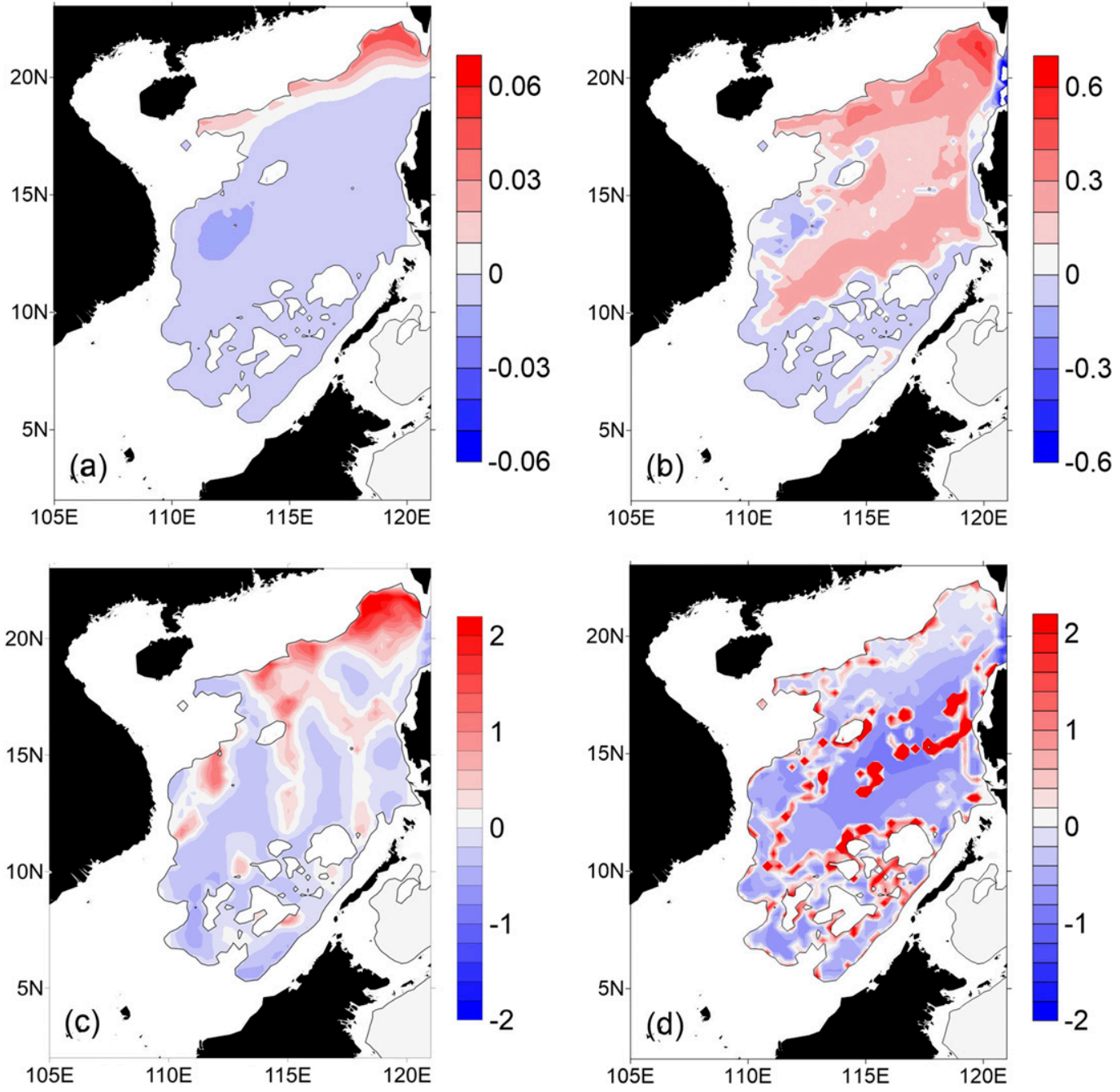

FIG. 5. As in Fig. 4, but for summer.

the cyclonic circulation in the deep SCS. The circulation pattern also significantly depends on the spatial distribution and temporal variability of the abyssal mixing, which will be further illustrated in the next section.

\section{c. Impact of spatiotemporal variability of mixing on the SCS abyssal circulation}

Mixing efficiency is conventionally approximated by a constant value near 1/6, but Mashayek et al. (2017) pointed out that the mixing efficiency is not a constant but varies significantly in the abyssal ocean and can be as large as about $1 / 3$ in stratified regions near topographic features. In the deep SCS, the turbulent mixing is found to be more active in the north than in the south and more active in the east than in the west, with two "hotspots" in the deep Luzon Strait and Zhongsha Islands area (Yang et al. 2016). Moreover, Wang et al. (2016) concluded that the tidal mixing in the SCS is stronger in summer than in winter due to a stronger stratification. In this section, the sensitivity of the SCS abyssal circulation to the spatiotemporal variability of mixing is examined by adopting $w_{m}$ based on Eq. (16).

After taking the spatiotemporal variability of mixing into account, the SCS abyssal circulation becomes more complicated (Figs. 2d and 3d). On the periphery of the basin-scale cyclonic circulation, there exist several subbasin-scale anticyclonic gyres. Different from the results based on Eq. (14), the SCS abyssal circulation is stronger in summer than in winter when Eq. (16) is used, which is consistent with the finding of Lan et al. (2015). Moreover, the upward EV between the middle and deep layers occurs over the slope regions and the island areas with the maximum of $2.0 \times 10^{-5} \mathrm{~m} \mathrm{~s}^{-1}$ (Fig. 4d), while the downward EV occurs in the interior basin with the maximum of about $-1.0 \times 10^{-5} \mathrm{~m} \mathrm{~s}^{-1}$ (Fig. 5d). In this case, the net upward flux between the middle and deep 

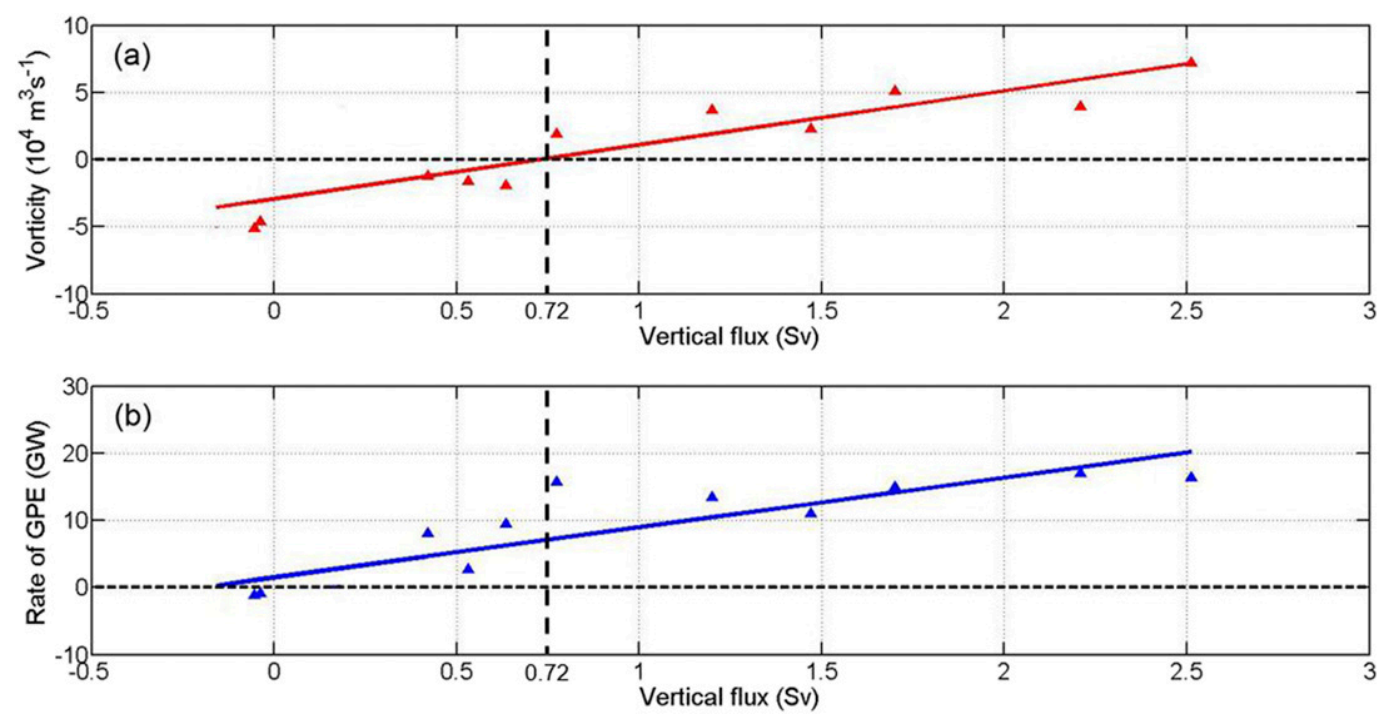

FIG. 6. (a) Regression relationship between the basin-integrated vorticity $\left(10^{4} \mathrm{~m}^{3} \mathrm{~s}^{-1}\right)$ of the deep circulation and the net flux (Sv) between the middle and deep layers of the SCS. (b) As in (a), but for that between the rate of GPE $(\mathrm{GW})$ and the net flux between the middle and deep layers of the SCS.

layers is $1.3 \mathrm{~Sv}$, and the corresponding rate of GPE and diapycnal diffusivity is $16.4 \mathrm{GW}$ and $1.3 \times 10^{-3} \mathrm{~m}^{2} \mathrm{~s}^{-1}$, respectively.

Furthermore, we calculated the meridional overturning streamfunction in the deep SCS as

$$
\psi(y)=\int_{x_{w}}^{x_{e}} h_{4} v_{4} d x .
$$

There is a basin-scale clockwise MOC in the deep SCS when the abyssal mixing is assumed to be uniform in time and space (Fig. 9a). However, the basin-scale clockwise MOC is divided into two subbasin-scale clockwise MOCs (Fig. 9b) when the spatiotemporal variability of abyssal mixing is considered, which is similar to the results based on the high-resolution global reanalysis data GLBa0.08 (Shu et al. 2014). It suggests that both the horizontal circulation and MOC in the deep SCS are significantly dependent on the spatiotemporal variability of the abyssal mixing.

\section{Discussion}

In this section, the vorticity analysis is conducted to explain the dynamics of how the abyssal mixing affects the multilayer SCS circulation. By calculating the curl of each term in Eq. (1), we present the vorticity equation in a unified format for all layers as

$$
\begin{aligned}
& \Omega_{\mathrm{ACC}}+\Omega_{\mathrm{ADV}}+\Omega_{\mathrm{COR}}+\Omega_{\mathrm{PG}}+\Omega_{U}+\Omega_{L} \\
& +\Omega_{\mathrm{HD}}+\Omega_{\mathrm{EDIME}}=0,
\end{aligned}
$$

where $\Omega_{U}$ is either the WS curl for the first layer or IF curl at the upper interface for other layers, and $\Omega_{L}$ is the sum of IF curl and BF curl at the lower interface of the layer. Similar to the results based on the three-layer model (Quan and Xue 2018), in the SCS basin where the water depth is more than $200 \mathrm{~m}$, the dominant terms in the vorticity balance for each layer are the PG curl $\left(\Omega_{\mathrm{PG}}\right)$ and COR curl $\left(\Omega_{\mathrm{COR}}\right)$, the sum of which is balanced by the WS curl $\left(\Omega_{\mathrm{WS}}\right)$ in the upper layer and by the HD curl $\left(\Omega_{\mathrm{HD}}\right)$ in the middle and deep layers, respectively. To show a clearer physical meaning, $\Omega_{\mathrm{PG}}$ is written as

$$
\Omega_{\mathrm{PG}}=\sum_{n=1}^{i} g_{n-1}^{\prime} J\left(\zeta_{n}, h_{i}\right)
$$

where $J(A, B)=A_{x} B_{y}-B_{y} A_{x}$ is the Jacobean operator. The right-hand side of Eq. (26) reflects the joint effect of baroclinicity and relief (JEBAR), which is generated by the interaction between baroclinic pressure and the variable topography (Mertz and Wright 1992). The term $\Omega_{\mathrm{COR}}$ can be divided into two terms as

$$
\Omega_{\mathrm{COR}}=-f \nabla \cdot h_{i} \mathbf{v}_{i}-\beta h_{i} v_{i} .
$$

Here, the first term on the right-hand side of Eq. (27) is the vortex stretching $\left(\Omega_{\mathrm{ST}}\right)$ and the second term is the planetary vorticity transport $\left(\Omega_{\mathrm{TR}}\right)$. Substitute Eq. (2) into Eq. (27) and omit the time derivative term to get

$$
\Omega_{\mathrm{COR}}=f\left(w_{i-1 i}-w_{i i+1}\right)-\beta h_{i} v_{i},
$$

which reflects the effect of EV on the vortex stretching. 

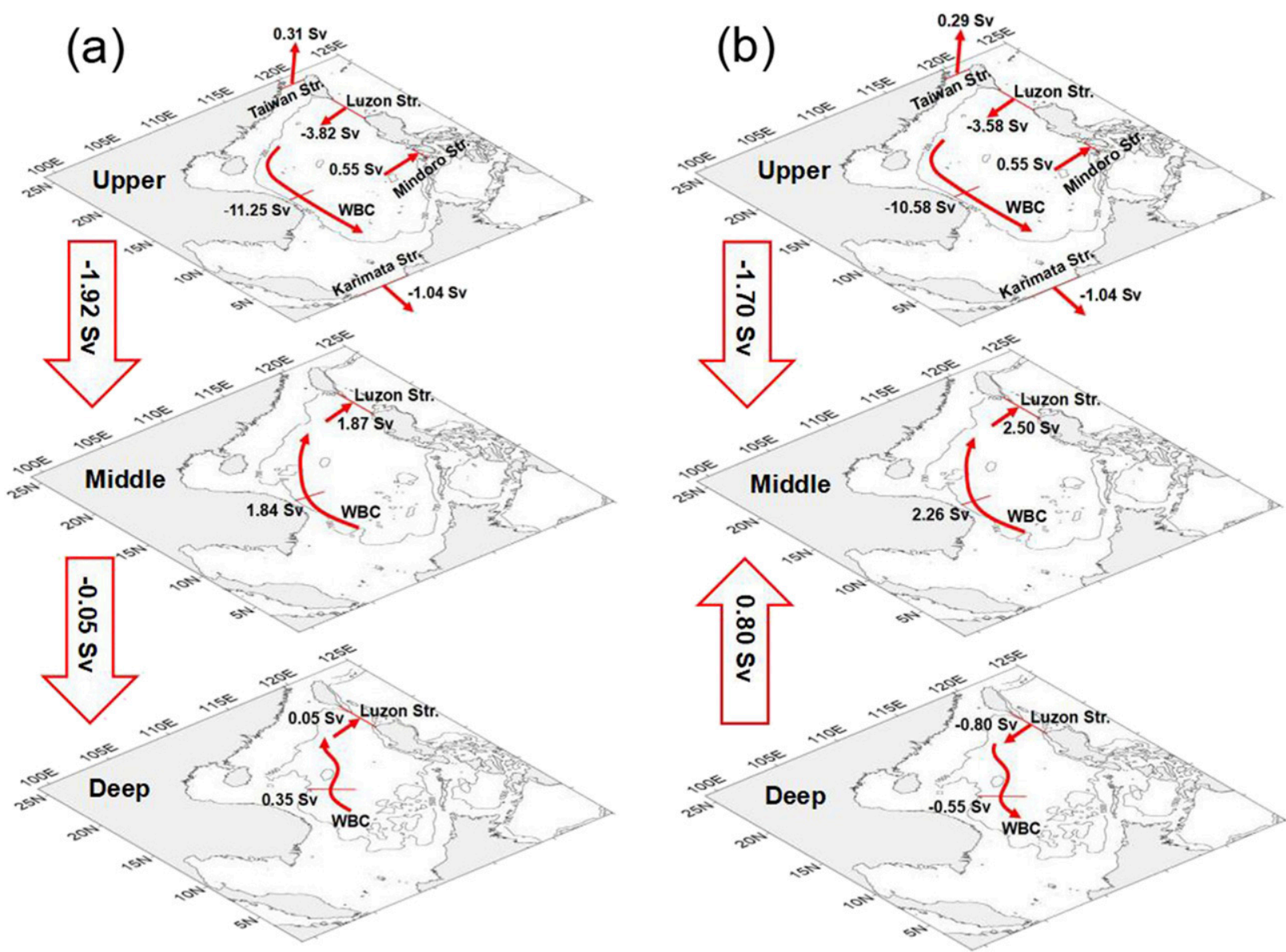

FIG. 7. Fluxes through the main straits, WBC transports at $13.5^{\circ} \mathrm{N}$ section, and fluxes between layers for (a) $Q=0$ and (b) $Q=1 \mathrm{~Sv}$.

Figure 10 shows the basin-integrated values of dominant terms in the vorticity balance for each layer. When $Q=0, w_{34}$ is so small that the vortex stretching is very weak $\left(\Omega_{\mathrm{ST}} \approx 0\right)$. Meanwhile, the horizontal gradient of the interface between the middle and deep layers is almost zero (i.e., $\nabla \zeta_{4} \approx 0$ ), which results in $g_{3}^{\prime} J\left(\zeta_{4}, h_{4}\right) \approx 0$. Hence, $\Omega_{\mathrm{PG}}$ in the deep layer is roughly equal to that in the middle layer (Fig. 10a). The PG force in the deep Luzon Strait points toward the Pacific Ocean (Fig. 11a), which drives the water to flow out of the SCS and leads to a negative $\Omega_{\mathrm{TR}}$. As a result, the sum of $\Omega_{\mathrm{PG}}$ and $\Omega_{\mathrm{COR}}$ in the deep layer is negative, and an anticyclonic circulation is required to produce a positive $\Omega_{\mathrm{HD}}$ for the vorticity balance.

As the abyssal mixing is strengthened, the interface between the middle and deep layers tends to be depressed in the central basin (not shown), which results in $\Omega_{\mathrm{ST}}>0$ and $\Omega_{\mathrm{PG}}<0$. The PG force in the deep Luzon Strait is reversed (Fig. 11b), which drives the water to enter the SCS, leading to $\Omega_{\mathrm{TR}}>0$. The sum of $\Omega_{\mathrm{PG}}$ and $\Omega_{\mathrm{COR}}$ in the deep layer is positive, and a cyclonic circulation is required to produce a negative $\Omega_{\mathrm{HD}}$ for the vorticity balance.

For the middle layer, the mixing-induced upward flux between the middle and deep layers makes $\Omega_{\mathrm{ST}}<0$ and $\Omega_{\mathrm{PG}}>0$, both of which are stronger than those when $Q=0$. Moreover, the increased outflux in the middle layer of the Luzon Strait (Fig. 7b) resulted in a stronger $\Omega_{\mathrm{TR}}$. Therefore, the anticyclonic circulation in the middle layer must be strengthened to produce a stronger $\Omega_{\mathrm{HD}}$ to balance the larger sum of $\Omega_{\mathrm{PG}}$ and $\Omega_{\mathrm{COR}}$.

In our previous study (Quan and Xue 2018), PG, which reflects the depth-integrated effect of the thickness variation across all layers, plays a key role in the dynamical link between layers. Although the upper layer is not affected directly by the abyssal mixing, the mixing-induced EV can redistribute the layer thickness to reduce $\Omega_{\mathrm{PG}}$ in the upper layer (cf. Figs. 10a and 10b) via the depth-integrated effect according to Eqs. (3) and (4). On the other hand, the weakened downward flux between the upper and middle layers and the influx in the upper layer of the 


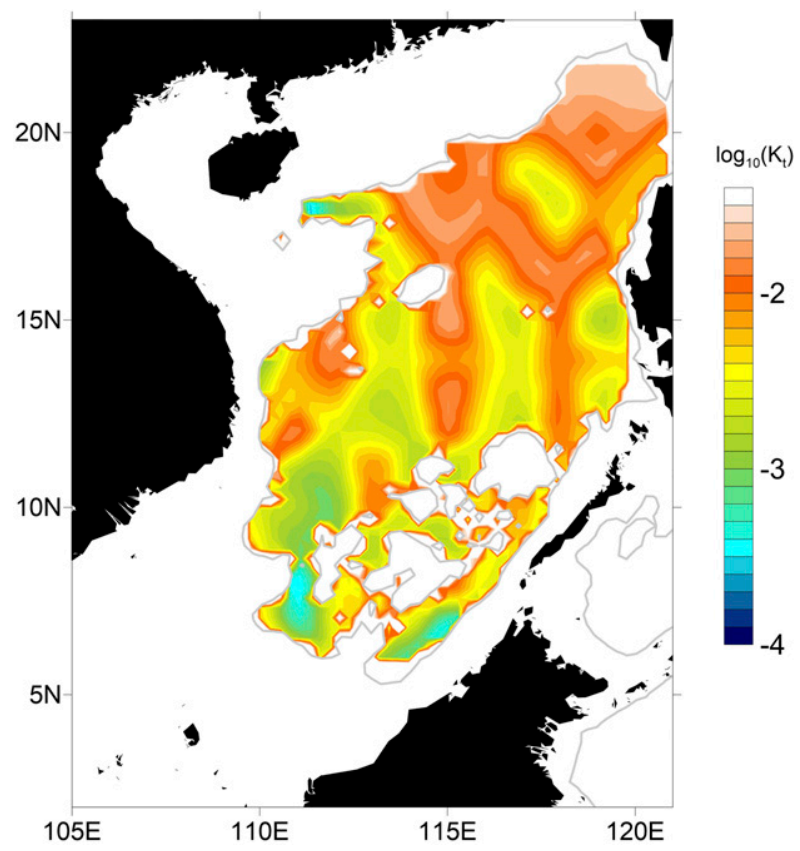

FIG. 8. Map of tide-induced, near-bottom, diapycnal diffusivity $\left(\mathrm{m}^{2} \mathrm{~s}^{-1}\right.$; logarithmic scale) read from Fig. 1 in Wang et al. (2017).

Luzon Strait (Fig. $7 \mathrm{~b}$ ) reduce $\Omega_{\mathrm{ST}}$ and $\Omega_{\mathrm{TR}}$. The damping of $\Omega_{\mathrm{PG}}$ is weaker than $\Omega_{\mathrm{COR}}$, hence the sum of them (negative), becomes larger than that when $Q=0$. As $\Omega_{\mathrm{WS}}$ (positive) is fixed, the cyclonic circulation in the upper layer must be weakened to produce a weaker $\Omega_{\mathrm{HD}}$ (negative) for the vorticity balance.

\section{Summary}

Using a modified four-layer model, the present study examines the influence of abyssal mixing on the multilayer SCS circulation. By parameterizing the mixing effect as the EV between the middle and deep layers of the SCS, it is found that the net upward flux should be at least $0.72 \mathrm{~Sv}$ (equivalent to a net input rate of GPE of $6.89 \mathrm{GW}$ or a diapycnal diffusivity of $0.65 \times 10^{-3} \mathrm{~m}^{2} \mathrm{~s}^{-1}$, respectively) for the generation of the cyclonic circulation in the deep SCS. Moreover, the abyssal mixing is able to intensify the anticyclonic circulation in the middle layer but weaken the cyclonic circulation in the upper layer. The tidal mixing in the SCS is stronger than the threshold to drive the cyclonic circulation in the deep layer, however, the pattern and evolution of the abyssal circulation and MOC are also found to significantly depend on the spatiotemporal variability of the mixing.

Based on the vorticity analysis, the mixing-induced upward flux can redistribute the thickness of the middle and deep layers and depress the interface between them in the central basin, which causes a PG force toward the SCS in the deep Luzon Strait to drive the overflow. As a result, a cyclonic circulation is required in the deep SCS to produce a negative $\Omega_{\mathrm{HD}}$ to balance the sum of $\Omega_{\mathrm{PG}}$ and $\Omega_{\mathrm{COR}}$. Meanwhile, the mixing-induced upward flux can also strengthen both $\Omega_{\mathrm{PG}}$ and $\Omega_{\mathrm{COR}}$ in the middle layer. Thus, a stronger anticyclonic circulation is needed there to intensify $\Omega_{\mathrm{HD}}$ for the vorticity balance. For the upper layer, the mixing-induced EV can redistribute the layer thickness to modulate PG. Since $\Omega_{\mathrm{Ws}}$ is fixed,
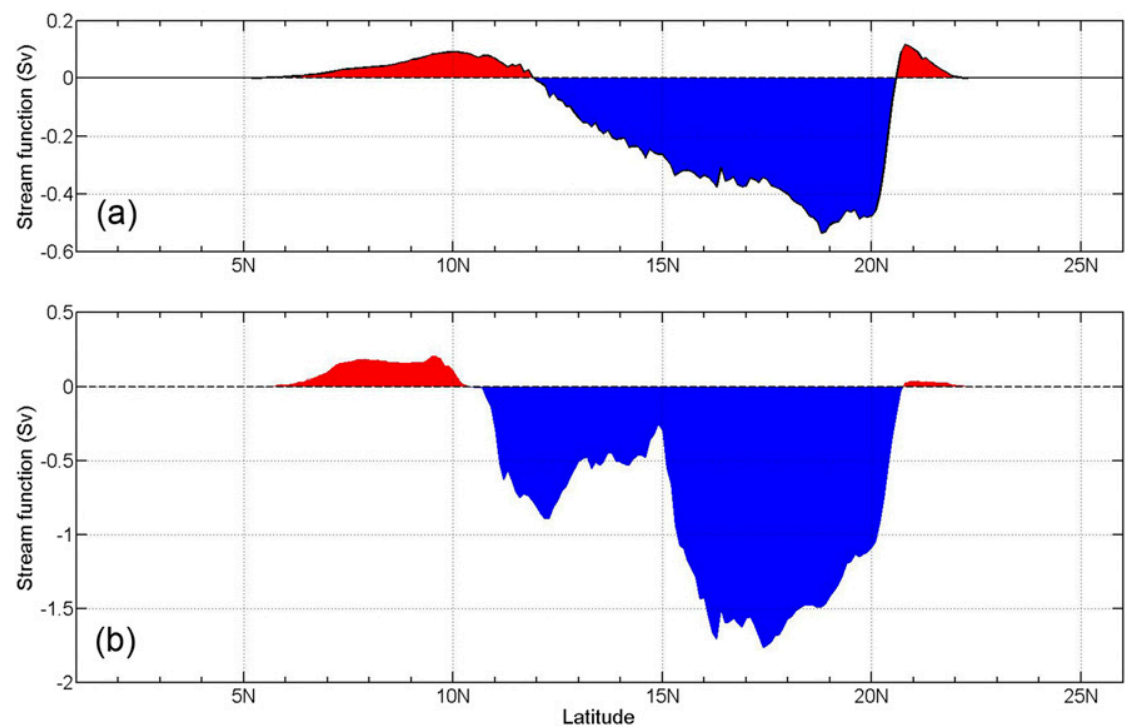

FIG. 9. Meridional overturning streamfunction (Sv) in the deep SCS for (a) $Q=1 \mathrm{~Sv}$ and (b) $Q=Q_{\text {SODA }}$. Negative (positive) values denote the clockwise (counterclockwise) MOC. 

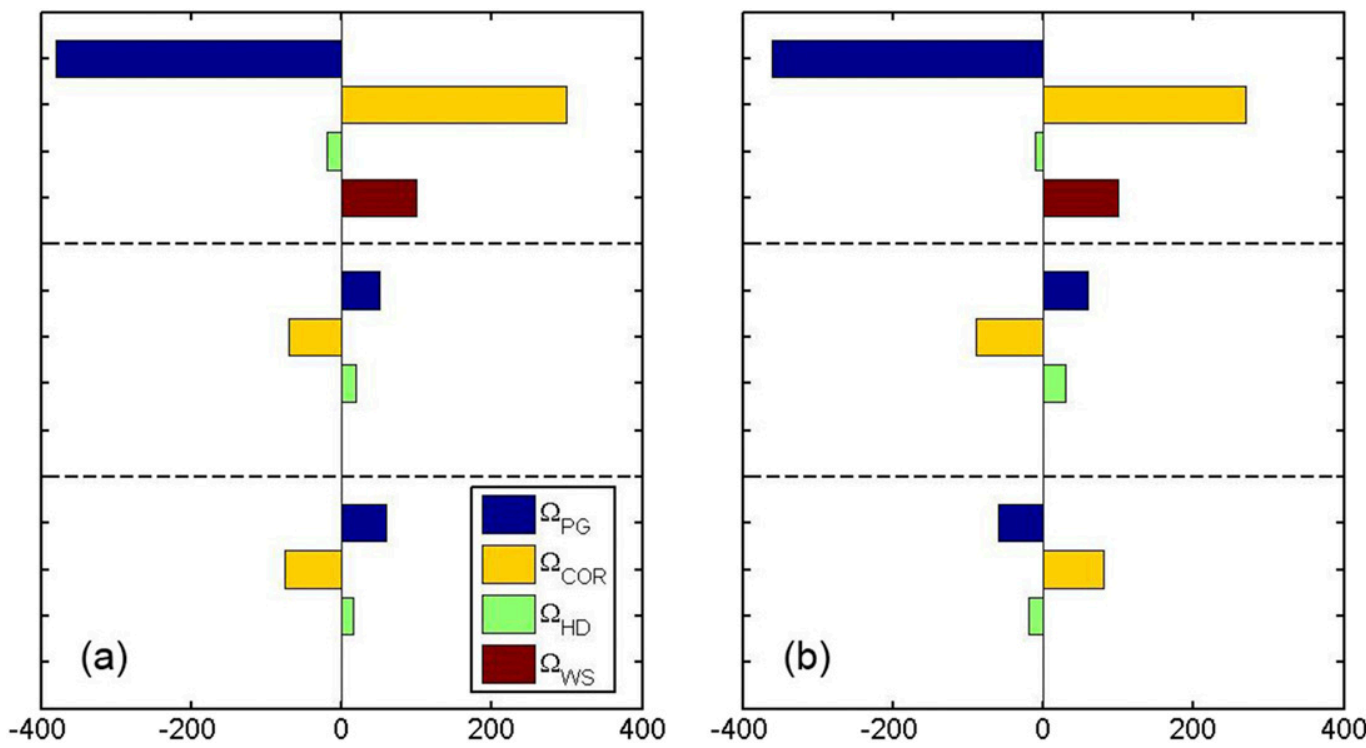

FIG. 10. Annual-mean dominant terms $\left(\mathrm{m}^{3} \mathrm{~s}^{-2}\right)$ in the basin-integrated vorticity equation of each layer for (a) $Q=0$ and (b) $Q=1 \mathrm{~Sv}$. From top to bottom, the upper, middle, and deep layers are separated from each other by the black dashed lines.

the cyclonic circulation there must be weakened to produce a weaker $\Omega_{\mathrm{HD}}$ to accommodate the larger sum of $\Omega_{\mathrm{PG}}$ and $\Omega_{\mathrm{COR}}$.

Our aim in this study is to illuminate the total effect of the abyssal mixing on a multilayer dynamical system, which may be extended to other marginal seas or some special areas in the open oceans where the mixing is as strong as that in the SCS (e.g., Ferron et al. 1998; Ledwell et al. 2000; Marshall and Speer 2012). It should be noted that the water mass transformation, which is closely associated with the mixing and significantly affects PG field in the SCS (Zhao et al. 2014; Wang et al. 2017), cannot be simulated by our present model since the density variation is not considered. Observations and a more comprehensive model (e.g., further development of the layered model to include thermodynamic and tidal forcing) are needed in our future study to achieve a better understanding of the role of mixing in the SCS dynamics.
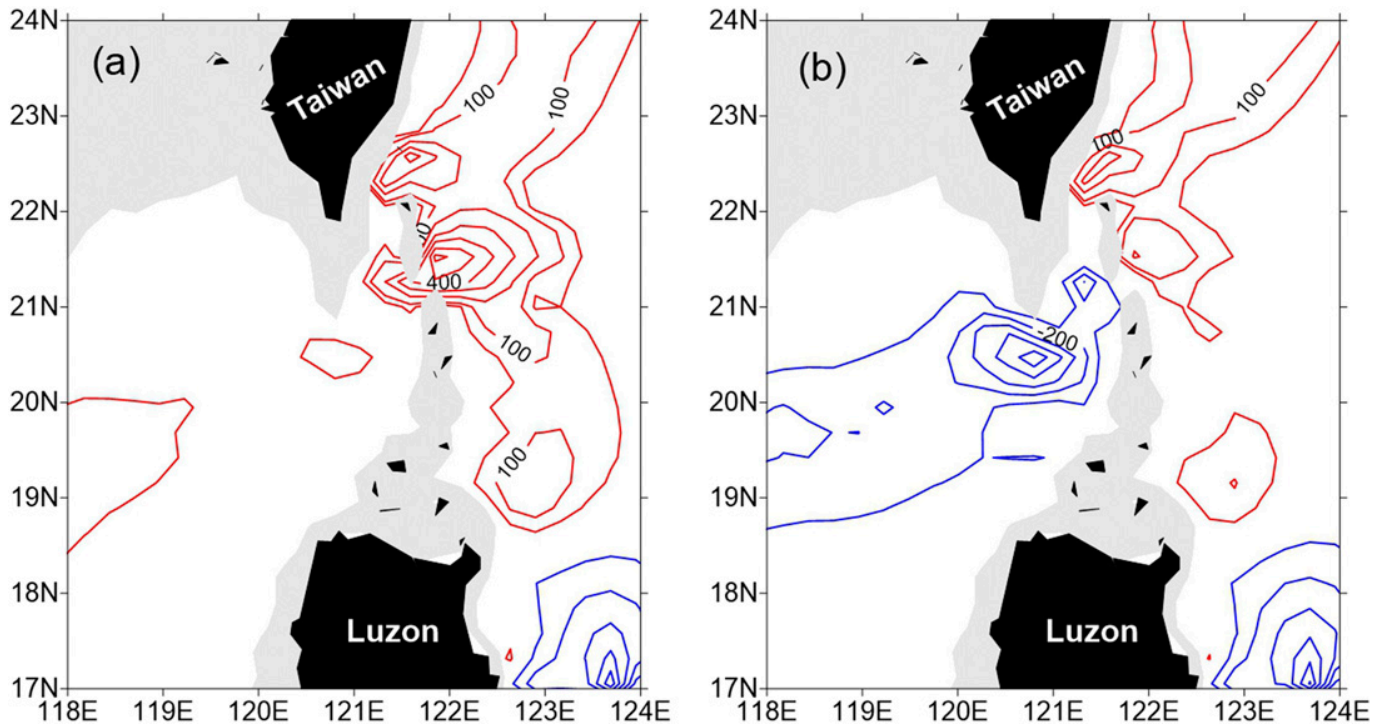

FIG. 11. Meridional component of PG force $\left(10^{-6} \mathrm{~m}^{2} \mathrm{~s}^{-2}\right)$ in the deep Luzon Strait for (a) $Q=0$ and (b) $Q=1 \mathrm{~Sv}$ Negative (positive) values in blue (red) contours represent the southward (northward) PG force component. 
Acknowledgments. The WOA13 data are downloaded from National Centers for Environmental Information (https://www.nodc.noaa.gov/OC5/woa13/). The CCMP wind data are available from Remote Sensing Systems (http://www.remss.com/measurements/ccmp). The ETOPO1 data are from the National Geophysical Data Center (https:// www.ngdc.noaa.gov/mgg/global/global.html). The SODA data are available from the Texas A\&M University Simple Ocean Data Assimilation website (http://soda.tamu.edu/). This study is supported by projects XDA10010304 and ISEE2018PY05 from the Chinese Academy of Sciences and 41476013 from the National Natural Science Foundation of China. We gratefully acknowledge the use of high performance computing clusters at the South China Sea Institute of Oceanology, Chinese Academy of Sciences. We thank two anonymous reviewers for their insightful comments, and Drs. Shantong Sun and Yukun Qian for discussions to improve this paper.

\section{REFERENCES}

Alford, M. H., 2010: Sustained, full-water-column observations of internal waves and mixing near Mendocino Escarpment. J. Phys. Oceanogr., 40, 2643-2660, https://doi.org/10.1175/ 2010JPO4502.1.

_- , and Coauthors, 2011: Energy flux and dissipation in Luzon Strait: two tales of two ridges. J. Phys. Oceanogr., 41, 2211-2222, https://doi.org/10.1175/JPO-D-11-073.1.

— , and Coauthors, 2015: The formation and fate of internal waves in the South China Sea. Nature, 521, 65-69, https:// doi.org/10.1038/nature14399.

—_ J. A. MacKinnon, H. L. Simmons, and J. D. Nash, 2016: Near-inertial internal gravity waves in the ocean. Annu. Rev. Mar. Sci., 8, 95-123, https://doi.org/10.1146/ annurev-marine-010814-015746.

Amante, C., and B. W. Eakins, 2009: ETOPO1 1 Arc-Minute Global Relief model: Procedures, data sources and analysis. NOAA Tech. Memo. NESDIS NGDC-24, National Geophysical Data Center, accessed 18 October 2015, https://doi.org/ 10.7289/V5C8276M.

Atlas, R., R. N. Hoffman, J. Ardizzone, S. M. Leidner, J. C. Jusem, D. K. Smith, and D. Gombos, 2011: A cross-calibrated, multiplatform ocean surface wind velocity product for meteorological and oceanographic applications. Bull. Amer. Meteor. Soc., 92, 157-174, https://doi.org/10.1175/2010BAMS2946.1.

Cai, S., X. Long, and S. Wang, 2007: A model study of the summer southeast Vietnam offshore current in the southern South China Sea. Cont. Shelf Res., 27, 2357-2372, https://doi.org/ 10.1016/j.csr.2007.06.002.

Carton, J. A., G. Chepurin, X. Cao, and B. S. Giese, 2000a: A Simple Ocean Data Assimilation analysis of the global upper ocean 1950-95. Part I: Methodology. J. Phys. Oceanogr., 30, 294-309, https://doi.org/10.1175/1520-0485(2000) $030<0294$ :ASODAA $>2.0 . \mathrm{CO} ; 2$.

,-- , and $-2000 \mathrm{~b}$ : A Simple Ocean Data Assimilation analysis of the global upper ocean 1950-95. Part II: Results. J. Phys. Oceanogr., 30, 311-326, https://doi.org/10.1175/ 1520-0485(2000)030<0311:ASODAA > 2.0.CO;2.
Chu, P. C., N. L. Edmons, and C. Fan, 1999: Dynamical mechanisms for the South China Sea seasonal circulation and thermohaline variabilities. J. Phys. Oceanogr., 29, 2971-2991, https://doi.org/ 10.1175/1520-0485(1999)029<2971:DMFTSC > 2.0.CO;2.

Ferron, B., H. Mercier, K. Speer, A. Gargett, and K. L. Polzin, 1998: Mixing in the Romanche fracture zone. J. Phys. Oceanogr., 28, 1929-1945, https://doi.org/10.1175/1520-0485(1998) 028<1929:MITRFZ>2.0.CO;2.

Gan, J., Z. Liu, and C. Hui, 2016: A three-layer alternating spinning circulation in the South China Sea. J. Phys. Oceanogr., 46 , 2309-2315, https://doi.org/10.1175/JPO-D-16-0044.1.

Gilson, J., and D. Roemmich, 2002: Mean and temporal variability in Kuroshio geostrophic transport south of Taiwan (1993-2001). J. Oceanogr., 58, 183-195, https://doi.org/10.1023/ A:1015841120927.

Guan, Y., and R. Huang, 2008: Stommel's box model of thermohaline circulation revisited-The role of mechanical energy supporting mixing and the wind-driven gyration. J. Phys. Oceanogr., 38, 909-917, https://doi.org/10.1175/2007JPO3535.1.

Huang, R., 1999: Mixing and energetics of the oceanic thermohaline circulation. J. Phys. Oceanogr., 29, 727-746, https://doi.org/ 10.1175/1520-0485(1999)029<0727:MAEOTO > 2.0.CO;2.

- 2009: Mixing and energetics of the oceanic circulation. Ocean Circulation: Wind-Driven and Thermohaline Processes, Cambridge University Press, 60-62.

Hurlburt, H. E., and J. D. Thompson, 1980: A numerical study of Loop Current intrusions and eddy shedding in Gulf of Mexico. J. Phys. Oceanogr., 10, 1611-1651, https://doi.org/10.1175/ 1520-0485(1980)010<1611:ANSOLC $>2.0 . C O ; 2$.

Jan, S., C. S. Chern, J. Wang, and S. Y. Chao, 2007: Generation of diurnal $\mathrm{K}_{1}$ internal tide in the Luzon Strait and its influence on surface tide in the South China Sea. J. Geophys. Res., 112, C06019, https://doi.org/10.1029/2006JC004003.

Jayne, S. R., 2009: The impact of abyssal mixing parameterizations in an ocean general circulation model. J. Phys. Oceanogr., 39, 1756-1775, https://doi.org/10.1175/2009JPO4085.1.

Jing, Z., and L. Wu, 2014: Intensified diapycnal mixing in the midlatitude western boundary currents. Sci. Rep., 4, 7412, https://doi.org/10.1038/srep07412.

Kraus, E. B., and J. S. Turner, 1967: A one-dimensional model of the seasonal thermocline II. The general theory and its consequences. Tellus, 19, 98-106, https://doi.org/10.3402/ tellusa.v19i1.9753.

Lan, J., N. Zhang, and Y. Wang, 2013: On the dynamics of the South China Sea deep circulation. J. Geophys. Res. Oceans, 118, 1206-1210, https://doi.org/10.1002/jgrc.20104.

_ , Y. Wang, F. Cui, and N. Zhang, 2015: Seasonal variation in the South China Sea deep circulation. J. Geophys. Res. Oceans, $\mathbf{1 2 0}$, 1682-1690, https://doi.org/10.1002/2014JC010413.

Large, W. G., J. C. McWilliams, and S. C. Doney, 1994: Oceanic vertical mixing: A review and a model with a nonlocal boundary layer parameterization. Rev. Geophys., 32, 363-403, https://doi.org/10.1029/94RG01872.

Ledwell, J. R., A. J. Watson, and C. S. Law, 1993: Evidence for slow mixing across the pycnocline from an open-ocean tracerrelease experiment. Nature, 364, 701-703, https://doi.org/ 10.1038/364701a0.

_ E. T. Montgomery, K. L. Polzin, L. C. St. Laurent, R. W. Schmitt, and J. M. Toole, 2000: Evidence of enhanced mixing over rough topography in the abyssal ocean. Nature, $\mathbf{4 0 3}$, 179-182, https://doi.org/10.1038/35003164.

Lien, R. C., T. Y. Tang, M. H. Chang, and E. A. D'Asora, 2005: Energy of nonlinear internal waves in the South China Sea. 
Geophys. Res. Lett., 32, L05615, https://doi.org/10.1029/ 2004GL022012.

Liu, Z., and J. Gan, 2017: Three-dimensional pathways of water masses in the South China Sea: A modeling study. J. Geophys. Res. Oceans, 122, 6039-6054, https://doi.org/10.1002/ 2016 JC012511.

Locarnini, R. A., and Coauthors, 2013: Temperature. Vol. 1, World Ocean Atlas 2013, NOAA Atlas NESDIS 73, 40 pp., http:// data.nodc.noaa.gov/woa/WOA13/DOC/woa13_vol1.pdf.

Marshall, J., and K. Speer, 2012: Closure of the meridional overturning circulation through Southern Ocean upwelling. Nat. Geosci., 5, 171-180, https://doi.org/10.1038/ngeo1391.

Mashayek, A., R. Ferrari, M. Nikurashin, and W. R. Peltier, 2015: Influence of enhanced abyssal mixing on stratification and the ocean overturning circulation. J. Phys. Oceanogr., 45, 2580-2597, https://doi.org/10.1175/JPO-D-15-0039.1.

— , H. Salehipour, D. B. Boudra, C. P. Caulfield, R. Ferrari, M. Nikurashin, W. R. Peltier, and W. D. Smyth, 2017: Efficiency of turbulent mixing in the abyssal ocean circulation. Geophys. Res. Lett., 44, 6296-6306, https://doi.org/10.1002/ 2016 GL072452.

McCreary, J. P., and P. K. Kundu, 1988: A numerical investigation of the Somali Current during the Southwest Monsoon. J. Mar. Res., 46, 25-58, https://doi.org/10.1357/002224088785113711.

__ and _ 1989: A numerical investigation of the sea surface temperature variability in the Arabian Sea. J. Geophys. Res., 94, 16 097-16114, https://doi.org/10.1029/JC094iC11p16097.

,-- , and R. L. Molinari, 1993: A numerical investigation of dynamics, thermodynamics and mixed-layer processes in the Indian Ocean. Prog. Oceanogr., 31, 181-244, https://doi.org/ 10.1016/0079-6611(93)90002-U.

McDougall, T. J., and W. K. Dewar, 1998: Vertical mixing and cabbeling in layered models. J. Phys. Oceanogr., 28, 1458-1480, https://doi.org/10.1175/1520-0485(1998) $028<1458$ :VMACIL>2.0.CO;2.

Mertz, G., and D. G. Wright, 1992: Interpretations of the JEBAR term. J. Phys. Oceanogr., 22, 301-305, https://doi.org/10.1175/ 1520-0485(1992)022<0301:IOTJT>2.0.CO;2.

Munk, W. H., 1966: Abyssal recipes. Deep-Sea Res., 13, 707-730, https://doi.org/10.1016/0011-7471(66)90602-4.

— and wind mixing. Deep-Sea Res. I, 45, 1977-2010, https:// doi.org/10.1016/S0967-0637(98)00070-3.

Nikurashin, M., and R. Ferrari, 2013: Overturning circulation driven by breaking internal waves in the deep ocean. Geophys. Res. Lett., 40, 3133-3137, https://doi.org/10.1002/grl.50542.

Niwa, Y., and T. Hibiya, 2004: Three-dimensional numerical simulation of $\mathrm{M}_{2}$ internal tides in the East China Sea. J. Geophys. Res., 109, C04027, https://doi.org/10.1029/2003JC001923.

Polzin, K. L., J. M. Toole, J. R. Ledwell, and R. W. Schmitt, 1997: Spatial variability of turbulent mixing in the abyssal ocean. Science, 276, 93-96, https://doi.org/10.1126/science.276.5309.93.

Qu, T., J. B. Girton, and J. A. Whitehead, 2006: Deepwater overflow through Luzon Strait. J. Geophys. Res., 111, C01002, https://doi.org/10.1029/2005JC003139.

Quan, Q., and H. Xue, 2018: Layered model and insights into the vertical coupling of the South China Sea circulation in the upper and middle layers. Ocean Modell., 129, 75-92, https:// doi.org/10.1016/j.ocemod.2018.06.006.

Rahmstorf, S., 2003: Thermohaline circulation: The current climate. Nature, 421, 699, https://doi.org/10.1038/421699a.

Scott, R. B., J. A. Goff, A. C. N. Garabato, and A. J. G. Nurser, 2011: Global rate and spectral characteristics of internal gravity wave generation by geostrophic flow over topography. J. Geophys. Res., 116, C09029, https://doi.org/10.1029/ 2011JC007005.

Shu, Y., H. Xue, D. Wang, F. Chai, Q. Xie, J. Yao, and J. Xiao, 2014: Meridional overturning circulation in the South China Sea envisioned from the high-resolution global reanalysis data GLBa0.08. J. Geophys. Res. Oceans, 119, 3012-3028, https:// doi.org/10.1002/2013JC009583.

St. Laurent, L. C., H. L. Simmons, and S. R. Jayne, 2002: Estimating tidally driven mixing in the deep ocean. Geophys. Res. Lett., 29, 2106, https://doi.org/10.1029/2002GL015633.

Stommel, H., and A. B. Arons, 1960: On the abyssal circulation of the world ocean-I. Stationary planetary flow patterns on a sphere. Deep-Sea Res., 6, 140-154, https://doi.org/10.1016/ 0146-6313(59)90065-6.

Talley, L. D., 2013: Closure of the global overturning circulation through the Indian, Pacific, and Southern Oceans: Schematics and transports. Oceanography, 26, 80-97, https://doi.org/ 10.5670/oceanog.2013.07.

Tian, J., Q. Yang, X. Liang, L. Xie, D. Hu, F. Wang, and T. Qu, 2006: Observation of Luzon Strait transport. Geophys. Res. Lett., 33, L19607, https://doi.org/10.1029/2006GL026272. and W. Zhao, 2009: Enhanced diapycnal mixing in the South China Sea. J. Phys. Oceanogr., 39, 3191-3203, https:// doi.org/10.1175/2009JPO3899.1.

Wang, G., D. Chen, and J. Su, 2006: Generation and life cycle of the dipole in the South China Sea summer circulation. J. Geophys. Res., 111, C06002, https://doi.org/10.1029/2005JC003314.

, S. Xie, T. Qu, and R. Huang, 2011: Deep South China Sea circulation. Geophys. Res. Lett., 38, L05601, https://doi.org/ 10.1029/2010GL046626.

Wang, X., S. Peng, Z. Liu, R. Huang, Y. Qian, and Y. Li, 2016: Tidal mixing in the South China Sea: An estimate based on the internal tide energetics. J. Phys. Oceanogr., 46, 107-124, https:// doi.org/10.1175/JPO-D-15-0082.1.

_ Z Z. Liu, and S. Peng, 2017: Impact of tidal mixing on water mass transformation and circulation in the South China Sea. J. Phys. Oceanogr., 47, 419-432, https://doi.org/10.1175/ JPO-D-16-0171.1.

Waterhouse, A. F., and Coauthors, 2014: Global patterns of diapycnal mixing from measurements of the turbulent dissipation rate. J. Phys. Oceanogr., 44, 1854-1872, https://doi.org/10.1175/ JPO-D-13-0104.1.

Wunsch, C., and R. Ferrari, 2004: Vertical mixing, energy, and the general circulation of the oceans. Annu. Rev. Fluid Mech., 36, 281-314, https://doi.org/10.1146/annurev.fluid.36.050802.122121.

Xiao, J., Q. Xie, C. Liu, J. Chen, D. Wang, and M. Chen, 2013: A diagnostic model of the South China Sea bottom circulation in consideration of tidal mixing, eddy-induced mixing and topography(in Chinese with English abstract). Acta Oceanol. Sin., 35, 1-13.

Xu, F., and L. Y. Oey, 2014: State analysis using the Local Ensemble Transform Kalman Filter (LETKF) and the threelayer circulation structure of the Luzon Strait and the South China Sea. Ocean Dyn., 64, 905-923, https://doi.org/10.1007/ s10236-014-0720-y.

Yang, H., L. Wu, S. Sun, and Z. Chen, 2015: Low-frequency variability of monsoon-driven circulation with application to the South China Sea. J. Phys. Oceanogr., 45, 1632-1649, https:// doi.org/10.1175/JPO-D-14-0212.1.

Yang, Q., J. Tian, and W. Zhao, 2010: Observation of Luzon Strait transport in summer 2007. Deep-Sea Res. I, 57, 670-676, https://doi.org/10.1016/j.dsr.2010.02.004. 
, W. Zhao, X. Liang, and J. Tian, 2016: Three-dimensional distribution of turbulent mixing in the South China Sea. J. Phys. Oceanogr., 46, 769-788, https://doi.org/10.1175/ JPO-D-14-0220.1.

Yaremchuk, M., and T. Qu, 2004: Seasonal variability of the large-scale currents near the coast of the Philippines. J. Phys. Oceanogr., 34, 844-855, https://doi.org/10.1175/1520-0485(2004) 034<0844:SVOTLC $>2.0$. CO;2.

—- J. McCreary, Z. Yu, and R. Furue, 2009: The South China Sea throughflow retrieved from climatological data. J. Phys. Oceanogr., 39, 753-766, https://doi.org/10.1175/ 2008JPO3955.1.

$\mathrm{Yu}, \mathrm{Z}$., S. Shen, J. P. McCreary, M. Yaremchuk, and R. Furue, 2007: South China Sea throughflow as evidenced by satellite images and numerical experiments. Geophys. Res. Lett., 34, L01601, https://doi.org/10.1029/2006GL028103.

_ J. P. McCreary, M. Yaremchuk, and R. Furue, 2008: Subsurface salinity balance in the South China Sea. J. Phys. Oceanogr., 38, 527-539, https://doi.org/10.1175/2007JPO3661.1.

Zhao, Z., V. Klemas, Q. Zheng, and X. Yan, 2004: Remote sensing evidence for baroclinic tide origin of internal solitary waves in the northeastern South China Sea. Geophys. Res. Lett., 31, L06302, https://doi.org/10.1029/2004GL021061.
Zhao, W., C. Zhou, J. Tian, Q. Yang, B. Wang, L. Xie, and T. Qu, 2014: Deep water circulation in the Luzon Strait. J. Geophys. Res. Oceans, 119, 790-804, https://doi.org/ 10.1002/2013JC009587.

Zhou, C., W. Zhao, J. Tian, Q. Yang, and T. Qu, 2014: Variability of the deep-water overflow in the Luzon Strait. J. Phys. Oceanogr., 44, 2972-2986, https://doi.org/10.1175/JPO-D-14-0113.1.

,,,---- X. Huang, Z. Zhang, and T. Qu, 2018: Observations of deep current at the western boundary of the northern Philippine Basin. Sci. Rep., 8, 14334, https://doi.org/ 10.1038/s41598-018-32541-9.

Zhu, Y., G. Fang, Z. Wei, Y. Wang, F. Teng, and T. Qu, 2016: Seasonal variability of the meridional overturning circulation in the South China Sea and its connection with inter-ocean transport based on SODA2.2.4. J. Geophys. Res. Oceans, 121, 3090-3105, https://doi.org/10.1002/2015JC011443.

_ J. Sun, Y. Wang, Z. Wei, D. Yang, and T. Qu, 2017: Effect of potential vorticity flux on the circulation in the South China Sea. J. Geophys. Res. Oceans, 122, 6454-6469, https://doi.org/ 10.1002/2016JC012375.

Zweng, M. M., and Coauthors, 2013: Salinity. Vol. 2, World Ocean Atlas 2013, NOAA Atlas NESDIS 74, 39 pp., http:// data.nodc.noaa.gov/woa/WOA13/DOC/woa13_vol2.pdf. 